\title{
Study on the Menu-Style Design Method of Rural Courtyard Landscape
}

\author{
Dan Li, Shuang Liang \\ Southwest University of Science and Technology, Mianyang, China \\ Email: 1162319964@qq.com
}

How to cite this paper: Li, D., \& Liang, S. (2020). Study on the Menu-Style Design Method of Rural Courtyard Landscape. Art and Design Review, 8, 199-207. https://doi.org/10.4236/adr.2020.83015

Received: July 15, 2020

Accepted: August 24, 2020

Published: August 27, 2020

Copyright ( 2020 by author(s) and Scientific Research Publishing Inc. This work is licensed under the Creative Commons Attribution International License (CC BY 4.0).

http://creativecommons.org/licenses/by/4.0/

\begin{abstract}
Rural courtyard is the most intimate space place for residents' "San Sheng (Production, life and ecology)" activities, and it's also an important part of rural landscape. Most rural courtyards face a series of problems, such as chaotic landscape, poor environment and difficult construction, which need to be solved urgently. This article takes the study of menu-style decoration as a starting point, introduces the ideas and advantages of the menu-type decoration, comparatively analyzes the problems of urban residences and rural courtyards, draws on the menu-type decoration mode, and attempts to build a set of menu mode suitable for rural courtyard landscape design.
\end{abstract}

\section{Keywords}

Rural Courtyard, Courtyard Landscape, Menu-Style

\section{Background}

In 2013, the Central Document No. 1 proposed the concept of building "beautiful countryside". The construction of beautiful countryside is an important part of the construction of beautiful China, and an upgraded version of new rural construction that conforms to the trend of social development. As the first space environment of rural residents' daily life, the rural courtyard is an indispensable part of the rural landscape. The construction of rural courtyard landscape is directly related to the improvement of rural residential environment and the realization of beautiful countryside's goals.

At the present stage, the development situation of rural courtyard in the vast areas of China is not optimistic. Dirty and messy courtyard landscape environment needs to be changed urgently; courtyard landscape construction pursues to be new and different, imitating urban villa courtyard landscape, copying the farmhouse and B \& B's courtyard pattern, the courtyard landscape gradually 
loses the local characteristics. Due to the economic conditions of villagers are limited, designers are unwilling to undertake rural design projects and rural government pays little attention to the courtyard environmental issues, which leads to the difficulties in the standardized design and construction of rural courtyard landscape. At the same time, menu-style decoration, its humanized menu decoration mode and centralized and unified decoration process not only healthily solved many problems caused by the decentralized decoration of rough house, but also better eased the contradiction between personalized decoration and industrialized decoration, which is the relatively scientific decoration mode in the residential decoration industry at present. Learning from the menu-style decoration, this article tries to explore a set of universal and flexible menu-style landscape design method system of rural courtyard, so as to provide feasible solutions to the rural courtyards' problems above-mentioned.

\section{Comparison of Menu-Style Decoration and Menu-Style Rural Courtyard Landscape Design}

\subsection{The Concept and Advantages of Menu-Style Decoration}

Most urban dwellings are small units, the pursuit of design style is not very strong. Homeowners are usually office workers, and their economic conditions are limited. At the time of housing decoration, decoration design, material purchase, quality inspection, acceptance payment and other aspects exhausting their energy, they are eager to liberate from the complicated decoration affairs. The chaos of decoration market, complex and diverse types of work, the uneven quality of decoration materials, expensive labor costs and so on let buyers feel that buying a house is easy and decoration is troublesome.

Menu-style decoration refers to a sales method in which a decoration company combines the decoration items and materials into different and fixed decoration products in advance, and compiles the products into a list, so that demanders can choose as if ordering in a restaurant (Yu et al., 2010). The basic contents include: a real estate developer or a housing construction organization entrusts a design institution to design several sets of residential decoration schemes for different house types to be selected by the householders. Each scheme also includes decoration menu of decoration items and unit price menu for the householders to choose. The householder participates in the design, that is to select the decoration scheme. Under the premise of ensuring the safety of building structure and reasonable pipeline layout, the householders are allowed to partially modify the design scheme or propose another scheme, determine the materials, colors and styles of the decoration items, and summarize them into a decoration order. Finally, according to the decoration menu selected by the homeowner, a professional decoration company organized by the developer centralizes the decoration within the specified time. At the same time, a supervision company can be introduced to ensure the quality of construction and the quality of incoming materials (Wang, 2001). 
Implementing menu-style decoration can effectively shorten the construction period, facilitate management and mortgage (Yang, 2002). It can meet the personalized needs of consumers, prevent the same decoration, so as to avoid demolition and secondary decoration after the householders' occupancy (Li, 2003), reduce the damage to the housing structure and building facade during the secondary decoration of rough house, improve the quality of residential decoration, help to standardize the residential decoration market and protect the rights and interests of consumers (Cao, 2002). Moreover, This kind of decoration also can lower the expenditure of the homeowners, promote the large-scale development of building materials, decoration equipment and other industries ( $\mathrm{Ma} \& \mathrm{Hu}$, 2003), strengthen the use and aesthetic functions of housing, guide the correct decoration concept (Wang, 2005), and reduce noise nuisance, resource waste and environmental pollution, which is conducive to the sustainable development of ecological environment.

\subsection{Introduction of the Menu-Style Design Method of Rural Courtyard Landscape}

The simple courtyard space structure is the same as that of small-sized urban house. The pursuit of personalized design style isn't intense and the emphasis on functional satisfaction is more emphasized. Most of the households in rural residences are farmers, and the limited economic conditions make them unable to afford high design expense, and the construction of courtyard landscape is mostly spontaneous behavior lacking the guidance of science and art (Chen, 2019). The construction concept of "heavy construction and light environment", poor knowledge of courtyard landscape design, difficult maintenance of plants in the later period, rough craft of courtyard construction and incomplete types of work and other reasons, which let them be deterred. Under the policy background of beautiful countryside, rural revitalization and so on, the government-led rural landscape construction focuses more on the village's public environmental issues, the written and strategic planning recommendations cannot effectively guide people to effectively upgrade the residential environment of courtyard (Chen, 2019). The courtyard landscape design is difficult to impel because the government, the designer and the owner cannot reach a consensus due to its belonging nature. The rural courtyard landscape construction blindly follows the trend to imitate the urban villa landscape so that the overall courtyard landscape doesn't adapt to the surrounding environment, this inadaptation makes the countryside features show a complex state without roots, and the simplicity of the rustic flavor is gradually missing (Wang \& Wang, 2014).

Menu-style decoration has been widely used in urban residential decoration market, but there are similar problems in rural courtyard construction and urban residential decoration. The menu mode of the decoration's method which mentioned above can be introduced into rural courtyard landscape design. Under the premise of protecting the integrity of rural landscape style and features, imagination of the menu-style rural courtyard landscape design method in this 
article is to determine the type of courtyard landscape style, to design different styles of courtyard landscape schemes combining with different courtyard space, and to provide the corresponding a courtyard landscape menu including courtyard landscape ornament varieties list, plant configurations table and quotation sheet. Villagers participate in the design, "ordering dishes", select and fine-tune the courtyard landscape design scheme and determine the favorite courtyard landscape ornaments and plant varieties, etc. Finally, the designers go to countryside to guide the construction. The rural government takes the lead in organizing the purchase of materials. The professional construction team stations in the village, and carry out the centralized construction of rural courtyard landscape according to the set landscape menu.

The application of menu-style rural courtyard landscape design method can meet individual design requirements and avoid the same courtyard landscape. The systematic simple design mode breaks the situation that difficult to design rural courtyard landscape. Its centralized design, collective construction and other modes are conducive to maintain uniformly, manage conveniently and save a lot of labor and material resources, which has the significance of promotion (Li, 2009). To some extent, it can control the cost of rural courtyard landscape construction, improves the ecological environment of rural courtyard, improve the quality of rural courtyard landscape, promote the quality of life and happiness of villagers, weaken the destruction of rural landscape bring by disorderly construction, promote the unity of rural landscape style and features, and provides feasible ideas and methods for the government to carry out rural landscape construction actions.

\section{Establishment of the System of Menu-Style Rural Courtyard Landscape Design Method}

Most of rural courtyards are mainly used by the villagers for their own production and life. The appearance and form of rural buildings are relatively simple, appearing in the shape of "L" letter and "Yi", "Ao" and "Hui" fonts which similar to Chinese characters, so which derives simple courtyard plan types (Figures 1-4). The menu-style courtyard landscape design mode serves ordinary residential courtyards, aiming at the common courtyard types, each type of courtyard as an independent whole is designed.

The design system of menu-style rural courtyard landscape includes two major sections: a menu system selected by consumers and a work system composed of the designers, rural government department and construction's teams. The menu system consists of two parts: required menu and self-selected menu. The two types of menus are to ensure that both the overall style and features of rural courtyard landscape are controllable and to meet the villagers' personalized needs for their own courtyard landscape. The work system put forward ideas in terms of personnel composition, personnel functions and operation procedures and other aspects. 


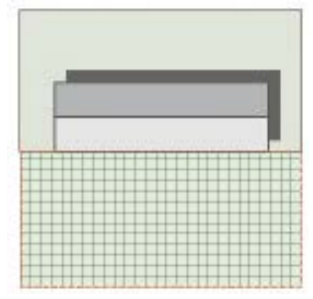

Figure 1. "Yi" font building courtyard.

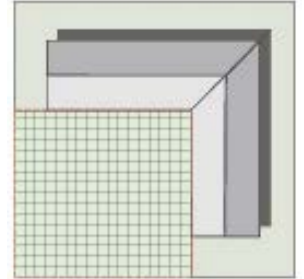

Figure 2. "L" letter building courtyard.

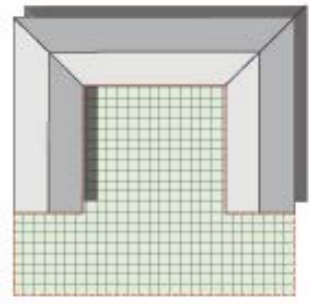

Figure 3. "Ao" font building courtyard.

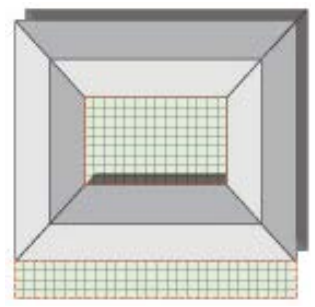

Figure 4. "Hui" font building courtyard.

\subsection{Required Menu Content}

Before setting the "dishes" of courtyard landscape menu, it's necessary to locate the "cuisine" of the landscape menu, that is, to locate the design style of the rural courtyard. In addition to satisfying the used needs of villagers, the rural courtyard landscape also plays an important role in maintaining the unity of the overall style and features of rural landscape. So, the required courtyard landscape menu is set to ensure that the construction of rural courtyard landscape can play a positive role in maintaining the rural features. Arranging, analyzing and summarizing the landscape elements of the local courtyard, and refining the menu-style feature items. Thereby, the required courtyard landscape menu is formed that contains landscape elements selection items affecting the rural features (Figure 5). 


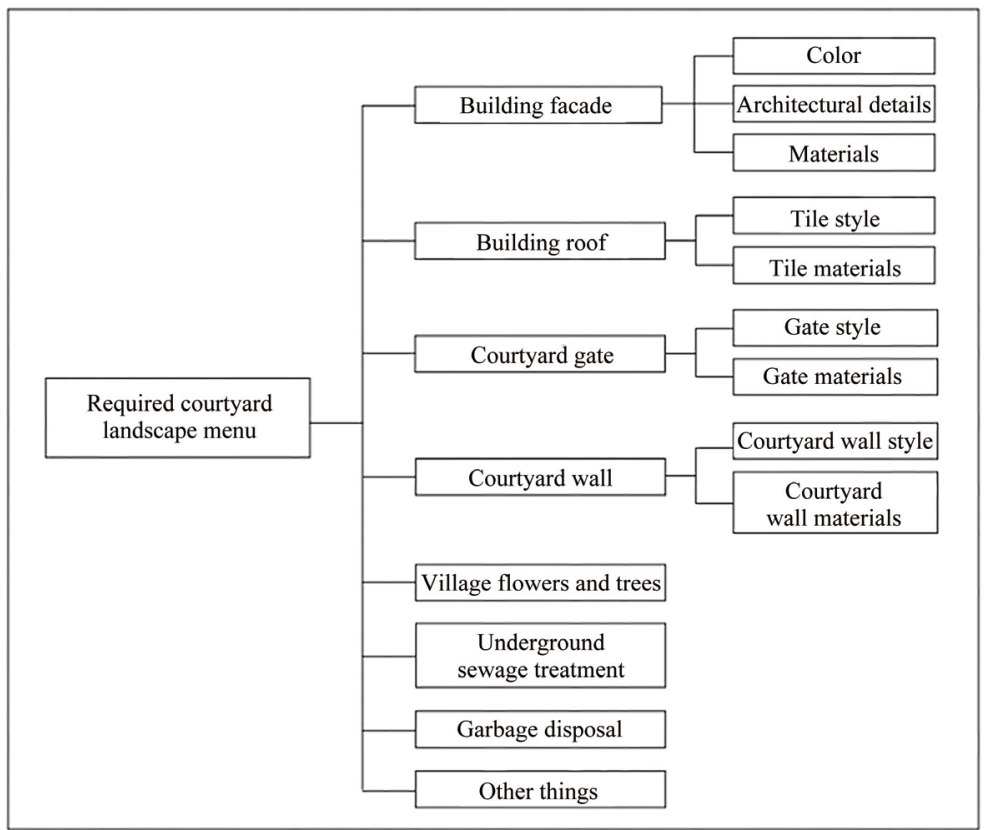

Figure 5. Framework system of required courtyard landscape menu (self-painted).

\subsection{Self-Selected Menu Content}

The diversity of courtyard landscape is reflected in the difference of different menus used in different courtyard space. The self-selected menu is to formulate different landscape strategies for different courtyard space and different levels of consumer groups, and to design different courtyard landscape. The self-selected courtyard landscape menu is divided into three levels of menus (Figure 6). First, the guarantee of courtyard function is the fundamental purpose of courtyard landscape construction ( $\mathrm{Li}, 2018)$. The first-class menu mainly sets the functional requirements of the courtyard, thus forming different functional space. The second-class menu derived from the first level menu is a refinement of specific courtyard landscape elements. Aiming at the different functional requirements of the first-class menu, the landscape elements included in it are listed in detail. The varieties and specific forms of each element are both detailed, or a variety of optimized combinations are designed in advance, which mainly including courtyard plants, landscape pieces, paving, ancillary facilities and other landscape elements. The three-class menu is the reference prices for corresponding decoration materials and landscape ornaments, and the cost budget of courtyard plants packages, including labor, greening and post-maintenance cost.

\subsection{Work Flow}

In order to make the menu-style courtyard landscape design method system work effectively, the designers, the villagers and the village government all have to participate in the whole work process. Among them, the designer analyzes the current characteristics of the rural courtyard and the villagers' living habits combined with the field research, determines the style of the 
rural courtyard, carries out the intending design of the courtyard scheme with the help of three-dimensional modeling technology, lets the courtyard landscape design schemes visible and popular (Zhao, 2016), and made an easy-to-understand courtyard landscape menu. Users participate in the design. According to their own needs and preferences, the villagers determine the courtyard functions and landscape elements combined with the landscape scheme and menu, just like "ordering dishes". The designers use two-dimensional drawing, three-dimensional modeling and other means to finish the functional partition of the courtyard and organically compose the landscape elements, perfect the courtyard landscape scheme, draw the courtyard construction drawing and make the material purchase list. The village government centrally organizes the procurement of materials, organizes the construction team to enter the construction site and supervises the construction progress and construction quality. The designers stationed at the site regularly to guide the construction of the courtyard landscape, adjust the plan in real time and supervise the construction quality (Figure 7). The later stage of the menu mode is promoted in the forms of the designer's practical application, the establishment of the villagers' word-of-mouth and the promotion of the government's policy, etc.

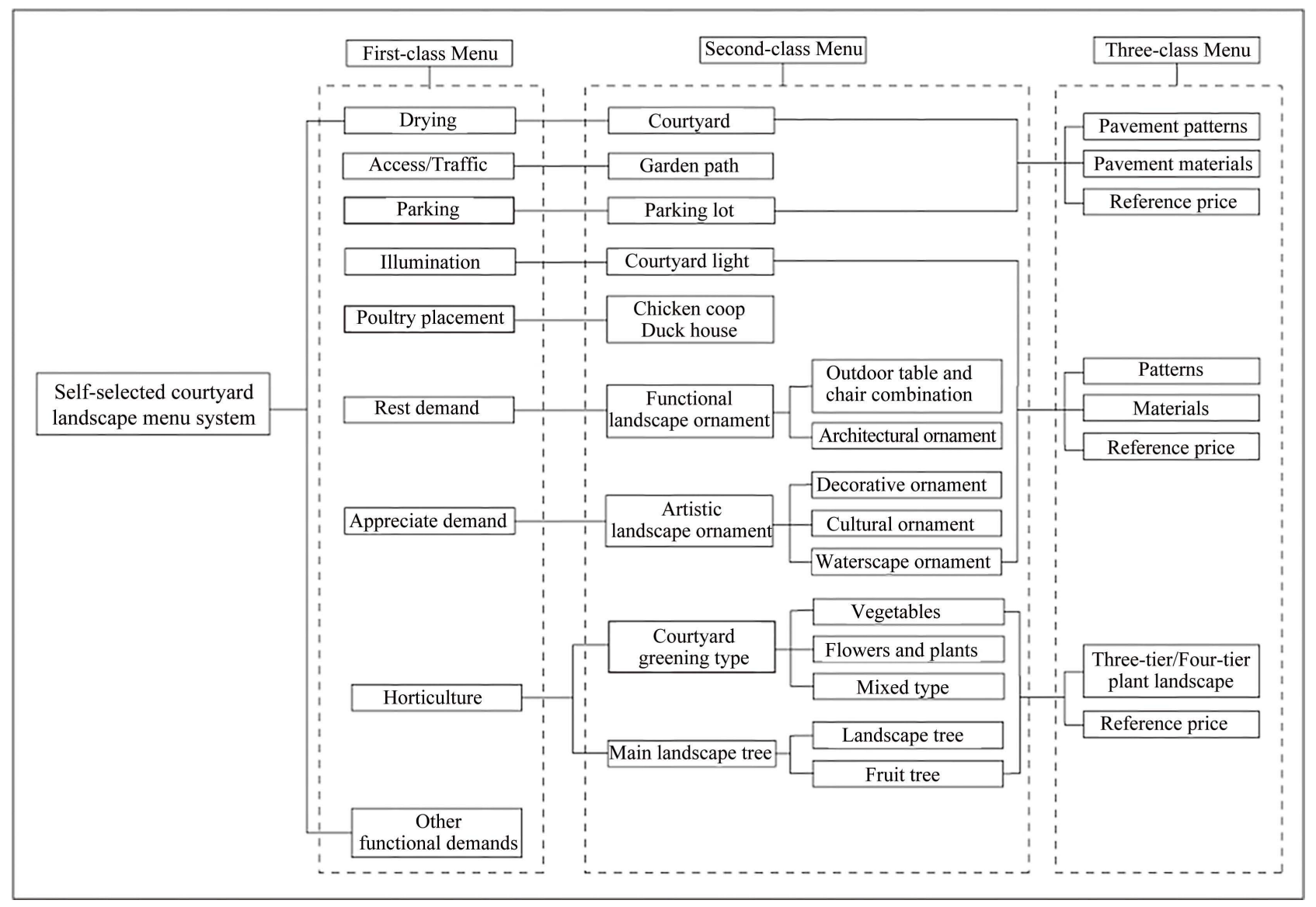

Figure 6. Framework system of self-selected courtyard landscape menu (self-painted). 


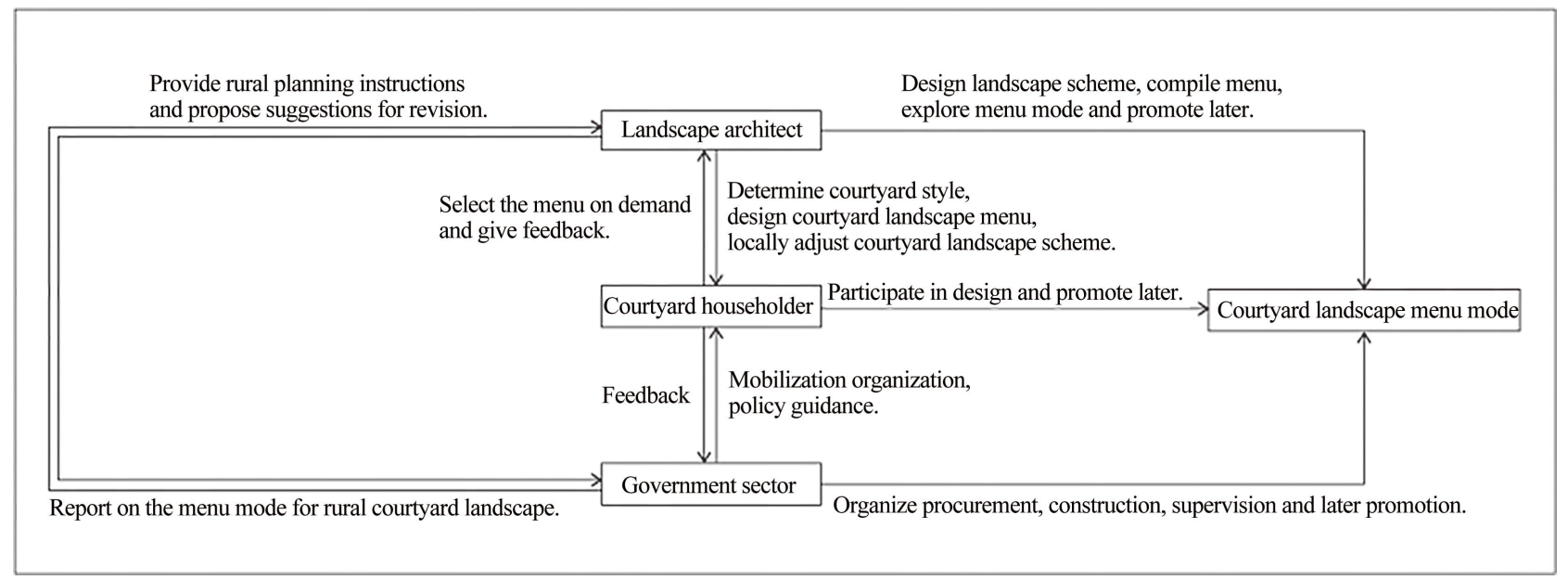

Figure 7. Work flow diagram of rural courtyard landscape design menu mode (self-painted).

\section{Summary and Outlook}

Courtyard is an important part of rural landscape. We should attach great importance to the landscape construction of this kind of "dot" space to improve the courtyard style and to enhance the overall quality of the rural landscape by fanning out from point to area (Fan et al., 2019). At this stage, due to funding and various realistic reasons, the application of traditional courtyard landscape design mode has been hindered in rural areas. In this paper, the menu-style courtyard landscape design method of the courtyard menu selected by villagers and the unified and standardized construction flow has strong practical significance in which improving the rural courtyard landscape environment, solving the dilemma of no one designing, standardizing courtyard construction mode, etc. But there are still deficiencies in standardization, systematization, operability and other aspects, we need to constantly improve it to form a more scientific menu's design system.

Well, the perfection and maturity of the menu-style courtyard landscape design method require the leadership of the rural government, the participation of relevant professionals and the active cooperation of rural residents. Only by constantly summing up experience and gradually forming a courtyard landscape design system led by the government, guided by experts and participated by villagers, can allow the majority of farmers to see the beautiful scenery at home.

\section{Conflicts of Interest}

The authors declare no conflicts of interest regarding the publication of this paper.

\section{References}

Cao, S. H. (2002). Talking about the Menu-Style Full Decoration Residence. Anhui Architecture, 9, 12.

Chen, H. W. (2019). Modular Design of Rural Courtyard in the Yangtze River Delta from the Perspective of Ecology: Taking Jiangshan Village, Gucheng Town, Nanjing City as 
an Example (pp. 341-359). Annual National Planning Conference 2019, Chongqing.

Fan, W. W., Chen, D. T., Wu, M., Nie, T. Y., \& Xing, Z. Y. (2019). Researches on Courtyard Landscaping Practices in Zhonghaoyu Village of Shandong Province under the Background of Rural Revitalization. Journal of Chinese Urban Forestry, 17, 60-64.

Li, H. X. (2009). Villa-Garden Landscape Design. Master's Thesis. Anhui: Hefei University of Technology.

Li, N. (2003). Research on the Condition and Explore the Way of House Decoration Development in Our Country. Master's Thesis. Chongqing: Chongqing University.

Li, W. J. (2018). The Design Method of the Garden Landscape of the Menu-Style Residential District: Taking Jinan City as an Example. Master's Thesis. Jianzhu: Shandong Jianzhu University.

Ma, C. J., \& Hu, X. M. (2003). After Implementing the Menu-Style Decoration Residence. Urban and Rural Development, No. 2, 62-63.

Wang, F. (2001). Talking about the Menu-Style Decoration of Residential District. Anhui Architecture, 8, 27.

Wang, Y. H. (2005). Research on the Industrialization System of Residence Whole-Decoration and Project Management. Master's Thesis. Nanjing: Nanjing Forestry University.

Wang, Z., \& Wang, T. (2014). Research on Zhejiang Rural Style and Space Construction Guidelines. Huazhong Architecture, 32, 94-98.

Yang, J. (2002). Study on Decoration Problems and Countermeasures of Newly-Built Commercial Residential Buildings: Analysis of "One-Time Implementation Detailed Rules of the Commercial Residential Decoration”. Journal of Architecture, No. 8, 12-13.

Yu, Z. M., Li, H., \& He, Z. Q. (2010). Tentative Discussion on the Platform Establishment of Overall Intelligent Menu-Type Decoration Model. Shanxi Architecture, 36, 234-235.

Zhao, Y. X. (2016). Research on Pattern of Architects Guide the Villagers to Participate in the Residence Design: With Yuanyang Hani New Residence Design as an Example. Master's Thesis. Kunming: Kunming University of Science and Technology. 